\title{
TERROR $^{*}$
}

\section{TERROR}

Sebastian Scheerer $^{* *}$

\section{RESUMO}

O que é terror e como ele se relaciona com a teoria política e com o direito? Em primeiro lugar, o terror garantiu o sucesso da revolução burguesa. Em segundo lugar, os governos ocidentais (e outros) exploram o medo do terror(ismo) para justificar reajustes autoritários. Terceiro, ao se rotular concorrentes ao poder como terroristas, ele se torna útil para defender posições privilegiadas. Em quarto lugar, o terror legitima extensões extralegais de poderes nas sociedades supostamente democráticas. Considerando tudo isso, o terror e o terrorismo têm maior chance de sobreviver no século XXI do que os ideais da teoria política clássica.

\section{PALAVRAS-CHAVE}

Terror. Terrorismo. Estado.

\begin{abstract}
What is terror, how does it relate to political theory and the law? First, terror ensured the success of the bourgeois revolution. Second, Western (and other) governments exploit the fear of terror(ism) to justify authoritarian re-adjustments. Third, labeling competitors for power as terrorists is useful to defend privileged positions. Fourth, it legitimizes extralegal extensions of powers in supposedly democratic societies. All things considered, terror and terrorism have a better chance of surviving the $21^{\text {st }}$ century than the ideals of classical political theory.
\end{abstract}

\section{KEYWORDS}

Terror. Terrorism. State.

\footnotetext{
* Publicado originalmente e com o mesmo título em: BRÖCKLING, Ulrich; KRASMANN, Susanne; LEMKE, Thomas (Hrsg.). Glossar der Gegenwart. Frankfurt am Main: Suhrkamp, 2004, S. 257-262.

Tradução: Raphael Boldt (Doutorando e Mestre em Direitos e Garantias Fundamentais pela Faculdade de Direito de Vitória (FDV, Vitória, ES, Brasil), com estágio doutoral na Johann Wolfgang Goethe-Universität (Frankfurt am Main). Pesquisador-bolsista da Fundação de Amparo à Pesquisa do Espírito Santo - FAPES). E-mail: raphaelboldt@hotmail.com

O tradutor agradece ao professor Sebastian Scheerer pela confiança demonstrada ao autorizar a tradução deste e de outros artigos de sua autoria e esclarece que, a pedido do próprio autor, a tradução deste artigo foi ligeiramente modificada com a exclusão de pequenos trechos, necessária para a adequada atualização do trabalho.

** Ex-diretor do Instituto de Criminologia da Universidade de Hamburgo e Professor do Departamento de Criminologia na mesma universidade (Hamburgo, Alemanha).E-mail: sebastian.scheerer@wiso.uni-hamburg.de
} 
Com o tempo, a linguagem cotidiana apoderou-se da palavra terror - basta pensar no discurso de tiranos domésticos que durante anos aterrorizaram suas esposas e seus filhos. Por isso, trata-se de um termo muito comum para classificar comportamentos violentos intoleráveis, em relação aos quais os atingidos se encontram praticamente indefesos.

Mas esse é apenas um reflexo opaco do sentido original bíblico da palavra latina terror. Esta designava o profundo sentimento de temor do homem no momento em que toma consciência de sua impotência diante da existência de um poder superior ameaçador. Também na vulgata, terror era uma forma ampliada de timor, não só medo e temor, mas o pavor da morte demonstrado pela criatura em face de um Deus raivoso (no Velho Testamento), o que não tem absolutamente nada a ver com a faceirice linguística e a atual tendência de dramatizar a designação de qualquer “sentimentozinho" (Nietzsche) como “terror”. Menos ainda era terror originalmente "uma forma violenta de luta política pelo poder, em particular o governo brutal de um ditador para manter o seu domínio” (Brockhaus).

Evidentemente, qualquer termo que se referisse a um extremo aumento do medo, era inicialmente negativo. Mas isso não impede, por si só, que se utilize esse sentimento em benefício próprio, para designar seus inimigos ou criar métodos para produzir esse sentimento. Terror não é apenas medo, ele também produz medo. Ele nunca se esgota na violência de materiais mortíferos, mas só se torna terror por meio da intenção de apresentá-lo a um público. Na instrumentalização da destruição psíquica, da qual alguém se vale para obter efeitos psicológicos nos outros, está a sua differentia specifica em relação a outras variantes políticas ou religiosas de emprego da violência. Em razão de utilizar por definição a violência psíquica para alcançar efeitos psicológicos em um determinado público (ou vários públicos), o terror está fadado ao palco e, por isso, sempre fez teatro. O teatro do terror é um espetáculo especial de pavor, seu cenário é o mundo real e suas mortes não são simuladas. O seu sentido, este teatro deve também à tríade de protagonistas, antagonistas e espectadores. Isso não impede que o medo também atinja os próprios atores - nem que as figuras sejam correlatas, mas orientadas por diferentes roteiros.

Esse tipo de "política simbólica” não separa o terror do funcionamento da política, senão o imita abertamente, demandando-o de uma maneira especial, pois não há nada pelo que a dominação política zele mais até os dias de hoje do que seu poder sobre as imagens. Entretanto, existem diversas formas de governar por intermédio do terror, como o governo original ou primário, 
mediante o exercício do terror contra o súdito. Como forma extrema de violência que explora o abalo dos sentimentos para fins políticos, o terror é o meio do estado de exceção por excelência. Ele também é relativamente fácil de justificar como ultima ratio para salvar os mais altos ideais em perigo. Foi esse o caso nos momentos críticos da Revolução Francesa, quando Robespierre elevou o terror ao máximo em seu governo, declarando: "Se a base da democracia em tempos de paz é a virtude, então, em tempos revolucionários há virtude e terror”; em tais momentos, ambos se relacionam: "Virtude! Sem ela, o terror é desastroso. E Terror! Sem ele, a virtude permanece impotente”. Antes e depois houve situações semelhantes: em 1683, Gottfried Wilhelm Leibniz sugeriu, como antídoto para o terror panicus que se abateu sobre as tropas cristãs ao verem os turcos e ouvirem a sua música, a neutralização do terror inimigo por meio de um terror ainda maior, que os oficiais deveriam gerar em seus próprios soldados. Não se deve esquecer a dedicação de Lenin ao "terror proletário, vermelho", ao "terror das massas” e à “desobstrução” para salvar a crescente necessidade da revolução.

Em contrapartida, como organização permanente, não se deve legitimar o terror. A sua institucionalização é um sinal de fraqueza. "Sans genié, sans talents, sans vertu il est aisé par la terreur” (Paul Henri Thiry d’Holbach, 1773). Só pode perenizá-lo quem consegue eximir-se do problema da legitimação, que silencia, encobre e transforma em tabu a sua existência. Por isso, Hitler ou Stalin, Idi Amin ou Pol Pot, Pinochet ou Varela, nunca iriam classificar suas medidas como terror - eram mais zelosos, com a designação de todos os potenciais opositores do regime como bandidos ou terroristas. Em qualquer caso, juridicamente, terroristas são elementos aptos a produzir institucionalização e legitimação. Pense-se no terror juridicizado da idade média ou no direito penal moderno, no territio sutilmente codificado, nas exibições dos instrumentos de tortura, ou na teoria da coação psicológica de Paul A. Feuerbach e seu mecanismo de ação central, a deterritio, ou seja, a dissuasão.

Na matriz da democracia contemporânea, o puro terror não possui um lugar próprio, talvez um ou outro elemento terrorista domesticado. Mas encontra-se aqui, acima de tudo, outra forma de governo, sutil, secundária: o governo por meio do fomento e da exploração do medo do terror. Assim, gera-se uma licença para deslocar o limite entre os poderes de intervenção do Estado e as liberdades civis. Utiliza-se a disposição dos cidadãos, no estado de exceção, em pagar por mais segurança com a moeda da liberdade, abdicando de direitos e liberdades que normalmente defenderiam com unhas e dentes. Para os governantes o terror não surge apenas como risco, mas 
também como chance, como uma espécie de deus ex machina, como potencial inimigo rentável, que pode facilitar a manutenção e a ampliação do seu poder. No plano global, o terror permite que a etapa da guerra tradicional entre Estados se transforme no alinhamento de todos os Estados contra um inimigo não estatal, bem como o fortalecimento de estruturas de poder verticais e a subordinação de Estados outrora soberanos ao comando de uma única liderança: o terror cumpre a função daquelas ameaças “externas”, sem as quais um sistema não pode se impor, estabelecer-se e se legitimar (HESS, 2003).

Além disso, o presente é caracterizado pelo desdobramento do discurso em uma violência material inimaginável. Como nunca antes, o próprio ato de classificação é utilizado como meio estratégico de poder. O fundamento dessa estratégia terciária de condução do conflito é a mudança em relação ao sentido e à função do conceito de terror. Se no passado a designação foi separada da valoração do fenômeno (de modo que se podia designar terror e eventualmente justificá-lo), atualmente designação e valoração tornaram-se apenas um. A classificação como terrorista também já carrega a valoração e, com ela, a debilitação da posição designada. Isso é possível apenas porque, mais do que nunca, o conceito é hoje relativo ao observador. Terror se tornou uma etiqueta que diz mais sobre o rotulado do que sobre o rótulo. O que para alguns é apenas uma conversa de grupo, para outros é um terror psicológico - o que para alguém é um combatente pela liberdade, na perspectiva do outro é um terrorista. Qual das etiquetas tem o poder para se tornar real é uma questão do poder de definição. Quem encontra reconhecimento como combatente pela liberdade, pode comprar armas, buscar aliados e permanecer sob a proteção do direito internacional. A quem o reconhecimento é negado, arrisca-se com a etiqueta de terrorista e, com isso, a sua própria existência. Assim, pode-se entender a frase: “terrorismo é a explicação maximalista do outro sob o ponto de vista de sua condição exterminável” (SLOTERDIJK, 2002, p. 26). O estigma torna o sujeito classificado como terrorista um fora da lei e ameaça com o mesmo destino qualquer um que se coloque ao seu lado.

O terrorista encarna o mal radical, a impossibilidade do diálogo e do reconhecimento - e isso tem implicações perigosas para os objetivos e os meios de reação. O objetivo não pode ser uma paz negociada, senão apenas a neutralização e, se necessário, a liquidação física. Como o terrorista parece um bárbaro que persegue seus objetivos fanaticamente com todos os meios viáveis, cuja violência sem sentido não poupa nem zonas neutras nem civis, com ele também não se negocia por meios civilizados. E para vencê-lo, os meios que se empregam no combate devem corresponder à 
natureza do terror. O que Jean Paul Sartre afirmara outrora, por ocasião da luta pela liberdade argelina para justificar o terrorismo - “ou se permanece aterrorizado ou se torna terrorista” acontece com o combate. Dificilmente o antiterrorismo consegue escapar da pressão pela imitação e da sofisticação e reprodução do terror. Chegamos então a um governo quaternário por meio do terror, com uma lógica de desenvolvimento regressivo: o terror regressa ao sistema que ele combate. "Por fim, chega-se ao ponto no qual a segurança e o terror formam um sistema mortal único, no qual eles legitimam e justificam suas ações mutuamente” (AGAMBEN, 2001). A rebarbarização da política passa, então, por condecoração de uma civilização bélica.

Nesse percurso, coloca-se no lugar de conservar todos os meios disponíveis contra os adversários demonizados - e assim fecha-se o círculo do governo primário por meio do terror. Logo, como todo terror é compreendido como terror contrário, concebe-se então não apenas terror contra terror, mas contamina-se também o terror daqueles contra os quais combate.

O terror representa uma ameaça existencial ao Ocidente e à globalização? Isso ainda é algo indefinido. O terror atual aponta para uma fase de ampliação do desconforto coletivo. Com a cortina de ferro, desapareceu um mapa cognitivo de referência; além disso, enquanto o tradicional sistema de segurança social titubeia criticamente, difunde-se o temor de uma multiplicação exponencial de riscos incontroláveis, desde a energia atômica até a manipulação genética. Para alguns, diante desse cenário, o terror marca uma progressão do risco anônimo - um estopim invisível que pode acender em qualquer lugar e a qualquer tempo; uma singularidade para além dessa parceria agonística, um amálgama de física e imaginação que aumenta de maneira imensurável a desorientação (a respeito, conferir BAUDRILLARD, 2003).

O terror pode ser interpretado como dupla instituição de ameaça e combate, de irritação e orientação - semelhantemente à dupla função eclesiástica: de um lado, medo na construção do inferno e, de outro, a suspensão deste com a construção da salvação. Prevalece, portanto, a sua função como ponto triangular no mapa cognitivo da aldeia global. Como satisfação do anseio infantil pelo bom Kasper $^{1}$, que com um grande bastão expulsa o malfeitor barbudo. O terror seria, portanto, uma oportunidade única de reindividualização do mal, cuja dissipação nunca teria sido superada no sistema, além de ser uma resposta para todos os anseios por reencantamento do mundo.

\footnotetext{
${ }^{1}$ Possivelmente a expressão Kasper seja uma referência à figura do famoso herói cômico do teatro de fantoches (Das Kaspertheater), conhecido nos países de língua alemã desde o final do século XVIII. (N. do T.)
} 
Talvez isso possa esclarecer por que do alarme contínuo decorrente do atual crescimento da ameaça terrorista subjacente aos extremistas islâmicos emana também uma estranha tranquilidade.

\title{
REFERÊNCIAS
}

AGAMBEN, Giorgio. Heimlich Komplizen. Über Sicherheit und Terror. In: Frankfurter Allgemeine Zeitung, 20 September, 2001.

BAUDRILLARD, Jean. Der Geist des Terrorismus. 2. Aufl. Wien: Hg. von Peter Engelmann, 2003.

HESS, Henner. Like Zealots and Romans: Terrorism and Empire in the 21st Century. In: Crime, Law and Social Change 39, 3391-357, 2003.

SARTRE, Jean-Paul. Vorwort. In: FANON, Frantz. Die Verdammten dieser Erde. Frankfurt am Main: Suhrkamp, 7-20, 1981.

SCHEERER, Sebastian. Die Zukunft des Terrorismus. Lüneburg: Drei Szenarien, 2002.

SLOTERDIJK, Peter. Luftbeben. An den Quellen des Terrors. Frankfurt am Main: 2002.

WALTHER, Rudolf. Terror, Terrorismus. In: BRUNNER, Otto; CONZE, Werner; KOSELLECK, Reinhart (Hg.). Geschichtliche Grundbegriffe. Historisches Lexikon zur politisch-sozialen Sprache in Deutschland. Bd. 6. Stuttgart, 1990, 323-444.

\section{TERROR}

\begin{abstract}
What is terror, how does it relate to political theory and the law? First, terror ensured the success of the bourgeois revolution. Second, Western (and other) governments exploit the fear of terror(ism) to justify authoritarian re-adjustments. Third, labeling competitors for power as terrorists is useful to defend privileged positions. Fourth, it legitimizes extralegal extensions of powers in supposedly democratic societies. All things considered, terror and terrorism have a better chance of surviving the 21st century than the ideals of classical political theory.
\end{abstract}

\section{KEYWORDS}

Terror. Terrorism. State. 